\title{
O Uso do Blog em Projetos Colaborativos a partir do Laptop Educacional
}

\author{
Juscileide Braga de Castro ${ }^{1,2,3}$, Renata Lopes Jaguaribe Pontes ${ }^{1}$, Andrea Pinheiro \\ Paiva Cavalcante ${ }^{1,2}$, José Aires de Castro Filho ${ }^{1}$ \\ ${ }^{1}$ Instituto UFC Virtual, Universidade Federal do Ceará (UFC). Av. Humberto Monte, \\ s/n, bloco 901, $1^{\circ}$ andar, Campus do Pici, CEP: 60.455-760 Fortaleza - CE - Brasil. \\ ${ }^{2}$ Doutoranda do Programa de Pós-Graduação em Educação Brasileira - Universidade \\ Federal do Ceará - Faculdade de Educação - Fortaleza - Ceará - Brasil. \\ ${ }^{3}$ Bolsista da Fundação Cearense de Apoio ao Desenvolvimento Científico e \\ Tecnológico-FUNCAP. \\ \{juscileide, renata, andrea, aires\}@virtual.ufc.br
}

\begin{abstract}
This article aims to describe how students and teachers from schools in the municipalities of Fortaleza and Barreira in the state of Ceará, awarded the UCA Project, using the blog as a tool for teaching and learning with the use of educational laptop. The methodology is qualitative in nature. The results showed that activities were developed with students, including not only the preparation and publication of content. It was found that blogging projects, used laptop from educational, enabled the expansion of learning spaces favoring the interactive communication, the extension of time and collaborative learning.
\end{abstract}

Resumo. Este artigo tem como objetivo relatar como alunos e professores de escolas dos municípios de Fortaleza e Barreira, no estado do Ceará, contempladas com o Projeto UCA, utilizam o blog como ferramenta de ensino-aprendizagem com o auxílio do laptop educacional. A metodologia adotada é de natureza qualitativa. Os resultados revelaram que foram desenvolvidas atividades com os estudantes, incluindo não somente a elaboração e publicação de conteúdo. Verificou-se que os blogs dos projetos, usados a partir do laptop educacional, possibilitaram a ampliação dos espaços de aprendizagem favorecendo a comunicação interativa, a ampliação do tempo e a aprendizagem colaborativa.

\section{Introdução}

A evolução das tecnologias digitais de informação e comunicação (TDIC) tem oportunizado mudanças na educação ao propiciarem novas formas de construção do conhecimento. Neste contexto, a proposta do Projeto Um Computador por Aluno (UCA) visa transformar as práticas tradicionais de ensino e aprendizagem, propondo novas formas de ensinar e aprender ao possibilitar a exploração pedagógica por meio da mobilidade do laptop educacional; a formação de comunidades de aprendizagem; a interação entre os sujeitos e a construção coletiva do conhecimento, nas quais professores e alunos podem explorar diferentes alternativas para uma mesma situação.

Dentre as alternativas possíveis de serem exploradas por meio do acesso à internet estão o blog, uma ferramenta advinda da chamada Web 2.0, tida como uma 
evolução da estrutura da internet que visa uma ampla participação dos usuários da rede por meio de canais colaborativos, nos quais eles podem atuar como emissores e produtores de conteúdo, estimulando a autoria, a interatividade e a socialização.

Segundo Silva (1998, s.p.) o conceito de interatividade remete a "qualquer coisa ou sistema cujo funcionamento permite ao seu usuário algum nível de participação ou de suposta participação". Para Lemos (1998), a interatividade é um caso específico de interação, a interatividade digital, que seria um diálogo entre homem e a máquina por meio de interfaces gráficas.

A Web 2.0 trouxe mudanças técnicas, mas, acima de tudo, ela gerou uma transformação social e cultural e mostrou a possibilidade de novas práticas, ao propiciar ao usuário uma maior participação por meio da produção de conteúdo, reconhecendo a sua autoria. Essa participação propicia uma interação social, por meio do armazenamento e compartilhamento de ideias, informações, enfim, conteúdos que podem ser construídos online de forma colaborativa.

Contudo, gerar novas possibilidades de práticas pedagógicas não é suficiente para que esses recursos sejam utilizados com fins de propiciar a interação e construção do conhecimento. É preciso que os professores conheçam as diferentes possibilidades pedagógicas do uso do blog e que a escola tenha acesso a computadores e a internet.

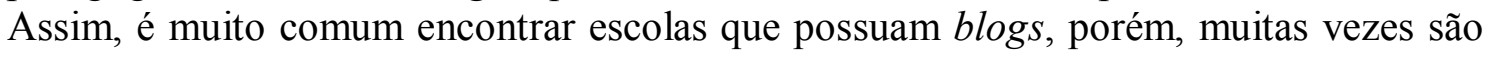
utilizados apenas para divulgar eventos ou como repositório de materias para os alunos.

Desta forma, pensando em uma melhor utilização dos recursos da Web 2.0, como o blog, os professores das escolas contempladas com o Projeto Um Computador por Aluno (UCA) recebem uma formação que contempla 5 módulos em um total de 180 horas. Dentro dessa formação, o módulo 2 trata da Web 2.0 e o módulo 4 aborda os projetos de aprendizagem considerando para isso a interdisciplinaridade [Marinho et al, 2011].

A partir do uso pedagógico do blog, este trabalho visa relatar como alunos e professores da educação básica de duas escolas, dos municípios de Fortaleza e Barreira, contempladas com o Projeto UCA, utilizam esse recurso da Web 2.0 como ferramenta de ensino-aprendizagem a partir do auxílio do laptop educacional.

$\mathrm{Na}$ próxima sessão discutir-se-á características da Web 2.0, assim como as possibilidades pedagógicas oportunizadas por essa nova fase da internet, sendo também abordados as novas formas de aprendizagem que se situam no contexto da sala de aula. Por último, detalhar-se-á o contexto e a metodologia utilizados seguidos da discussão das análises e as conclusões da pesquisa.

\section{Web 2.0: aprendizagem e o uso do computador na Educação}

Vários teóricos [Marinho et al, 2009; Solomon e Schrum, 2007; Richardson, 2006] apontam que o surgimento e o desenvolvimento da Web 2.0 possibilitaram novas e estimulantes oportunidades para a educação, ao propor alterações nos paradigmas tradicionais de ensino e aprendizagem, em que ainda prevalece a educação centrada no ensino e na transmissão de conhecimento, para uma educação mais centrada na aprendizagem.

Ao possibilitar que o sujeito seja autor do seu próprio conhecimento, a Web 2.0 estimula a formação de um ser autônomo, pensante, reflexivo e crítico que, ao mesmo tempo em que compartilha em rede suas descobertas, aprende com as dos outros. No contexto educacional, essa característica possibilita que o aluno aprenda com o 
professor; que o professor aprenda com o aluno e que os alunos aprendam entre si, resultando em uma educação dialógica na qual, segundo Freire (1996, p.23), "quem ensina aprende ao ensinar e quem aprende ensina ao aprender".

Uma das ferramentas "mais amplamente adotada na read/write Web até o momento" [Richardson, 2006, p.8] e um dos serviços que melhor exemplificam a Web 2.0 são os weblogs, palavra composta por web, que significa as páginas na internet, e $\log$, que significa registro, ou seja, um registro na web. A estrutura do blog disponibiliza espaços para a escrita das postagens (ou posts) que são mensagens de texto que podem ter imagens, vídeos e hiperlinks. Para cada postagem há um espaço para os comentários sobre a mesma, em um local onde se pode dialogar com o autor e vice-versa, concordando, discordando ou acrescentando alguma outra discussão ou elemento, como por exemplo, um hiperlink para outro blog que discuta outro ponto de vista sobre a temática abordada.

Pode-se afirmar que o blog ocupa um lugar de destaque no contexto educacional. Barbosa e Granado (2004, p.69) concordam com essa afirmação asseverando que "se há alguma área onde os weblogs podem ser utilizados como ferramenta de comunicação e de troca de experiências com excelentes resultados, essa área é, sem dúvida, a da educação".

Nessa perspectiva, Marinho et al (2009) explicam que criar um blog é uma boa estratégia para o professor inserir-se de forma ativa na rede, iniciando sua cultura de uso de recursos da Web 2.0. Esse uso irá deixá-lo mais confortável para aplicá-lo juntos aos alunos, já que teria maior familiaridade com o recurso. Assim, os professores teriam maiores condições de orientar o uso de blogs pelos alunos, possibilitando que os alunos aproveitem essas ferramentas disponíveis na web, tanto em casa quanto na escola [Solomon, Schrum, 2007].

Contudo, a despeito das possibilidades de uso das ferramentas da Web 2.0 na escola, não basta incorporar os computadores às rotinas escolares. "A tecnologia em si não modifica a natureza da educação escolar. $\mathrm{Na}$ melhor das hipóteses, amplifica processos já em andamento" [Warschauer, 2006, p.184].

Para Sibilia (2012) e Warschauer (2006): o uso da tecnologia na escola precisa estar amparado por um projeto pedagógico inovador. Sibilia (2012) defende que é necessário preparar os estudantes para saber usar o acesso ao fluxo possibilitado pela conectividade dos computadores que estão na sala de aula, nos moldes do Projeto UCA.

É oportuno também ressaltar a interação e a interatividade, mencionadas por Silva (2010, p.82), para quem a escola não está em sintonia com tais questões "porque está fechada em si mesma, em seus rituais de transmissão, quando o seu entorno modifica-se em nova dimensão comunicacional". O autor considera que o hipertexto convoca o espectador a uma atuação híbrida, múltipla, de emissão e recepção.

À medida que faz uso das tecnologias hipertextuais, o estudante tende a tornarse menos passivo diante da separação da produção e consumo, da separação da distribuição e comunicação. Aprende que dele mesmo depende o gesto instaurador que cria e alimenta a experiência comunicacional entendida como diálogo com e na multiplicidade. Aprende a não aceitar passivamente o que é transmitido. "Diante da informação, da mensagem, pode interferir, modificar, produzir e compartilhar" [Silva, 2010, p.17].

Muito já se comentou sobre a distância entre o que a escola propõe como aprendizagem e que estratégias são mobilizadas com esse fim e a vida cotidiana. Desse 
"abismo" decorre, de modo geral, um sentido de inutilidade e de irrelevância para o que se aprende na escola. Sem contar que a aprendizagem ainda é encarada como processo de ordem individual [Wenger , 2001].

Aprender não é um processo individualizado, mas como propõem Lave e Wenger (1991), trata-se de um processo que se organiza a partir da participação, isto é, na mediação de diferentes perspectivas entre os coparticipantes. Portanto, o que propõe a aprendizagem colaborativa com suporte computacional é que o processo de aprendizagem ocorra na atuação coletiva do grupo, na prática em si. Para essa abordagem, questões como a intersubjetividade tem significado especial, posto que coloca em evidência a aprendizagem constituída pela interação. "Esta é a aprendizagem que não se realiza simplesmente na interação, mas que está realmente constituída nas interações entre participantes" [Stahl et al, 2006, p.12].

Do ponto de vista da aprendizagem, como já exposto anteriormente, não será a simples aquisição de equipamentos que implicará na melhoria da qualidade da educação oferecida. "Os laptops poderão fazer uma boa escola melhor, mas não poderão fazer uma escola ruim se tornar uma boa escola" [Warschauer, 2006, p.34-35]. A seguir será apresentado o contexto da pesquisa e a metodologia.

\section{Contexto e Metodologia da Investigação}

Com o objetivo de relatar a utilização do blog como ferramenta de ensino-aprendizagem por alunos e professores dos municípios de Fortaleza e Barreira, foi realizada uma pesquisa qualitativa que terá como estratégia o estudo de caso. Ludke e André (1986) afirmam que a concepção do estudo de caso não advém de uma visão predeterminada da realidade, mas visa apreender os aspectos ricos e imprevistos que envolvem uma determinada situação.

Elegeu-se como técnicas de coletas de dados a observação e a análise de conteúdo, uma técnica que permite a descrição sistemática, objetiva e quantitativa do conteúdo da comunicação [Lakatos e Marconi, 1991]. Pretendeu-se, assim, analisar blogs criados para o desenvolvimento de projetos no âmbito do Projeto UCA. Para isso, foram analisados os seguintes blogs:

1. Projeto nossos lugares no mundo (http://nossoslugaresnomundo.blogspot.com.br/): Esse $b \log$ foi construído para a realização de um projeto com o objetivo de possibilitar o contato e a interação entre os alunos das escolas UCA de Barreira (Escola Escola Antônio Julião Neto) e Fortaleza (EMEIF Monteiro Lobato).

O projeto foi realizado com crianças do $5^{\circ}$ ano do Ensino Fundamental do turno da tarde, contando, também, com a participação de estudantes norte-americanos de um projeto de intercâmbio do grupo de Pesquisa e Produção de Ambientes Interativos e Objetos de Aprendizagem (PROATIVA ${ }^{1}$ ).

Dentre os resultados obtidos, o projeto possibilitou o desenvolvimento de aprendizagens acerca das culturas de cada localidade, assim como a valorização de cada cultura, proporcionando a convivência adequada com a diversidade cultural [Lima et al, 2011].

2. Projeto Um Mundo Informações (http://1mundodeinformacoes.blogspot.com.br/search/label/Escola\%20Monteiro\%20Lo

\footnotetext{
${ }^{1}$ http://www.proativa.vdl.ufc.br/
} 
bato): Esse blog foi construído para servir como um portal de notícias, tendo como principal objetivo melhorar a aprendizagem dos alunos na área do Tratamento da Informação, bloco pertencente ao currículo de Matemática e que trabalha com o uso de gráficos. Realizado nos meses de setembro a dezembro de 2011, o projeto teve a participação direta dos estudantes do $5^{\circ}$ ano do Ensino Fundamental do turno da manhã da EMEIF Monteiro Lobato (Fortaleza), além da participação indireta de todo o corpo docente, discente e comunidade escolar que participaram respondendo perguntas e fornecendo entrevistas.

Dentre os resultados obtidos, o projeto proporcionou a combinação de diferentes linguagens e tecnologias, de modo a integrar ao currículo escolar, favorecendo a apropriação tecnológica e a formação cidadã [Castro, Castro-Filho, 2012]. A seguir serão apresentados os resultados que emergiram das análises.

\section{Resultados: experiências com o uso do blog em escolas UCA}

Os resultados das análises realizadas nos blogs dos projetos, já descritos anteriormente, demonstraram formas diferentes de utilização do blog como ferramenta de ensino-aprendizagem. Os resultados serão apresentados em cinco categorias: comunicação interativa, ampliação do tempo, ampliação do espaço, produção de materiais e aprendizagem colaborativa, as quais serão apresentadas e discutidas a seguir.

\subsection{Comunicação interativa}

Observou-se, nos blogs analisados, que os estudantes não se comportaram passivamente ao que era divulgado nos $b \log s$, mas acrescentavam, modificavam, isto é, interferiam nas postagens através dos comentários que eram publicados, omitindo opiniões, fazendo perguntas ou acrescentando algo ao que era postado, como pode ser visualizado nas figuras 1 e 2 .

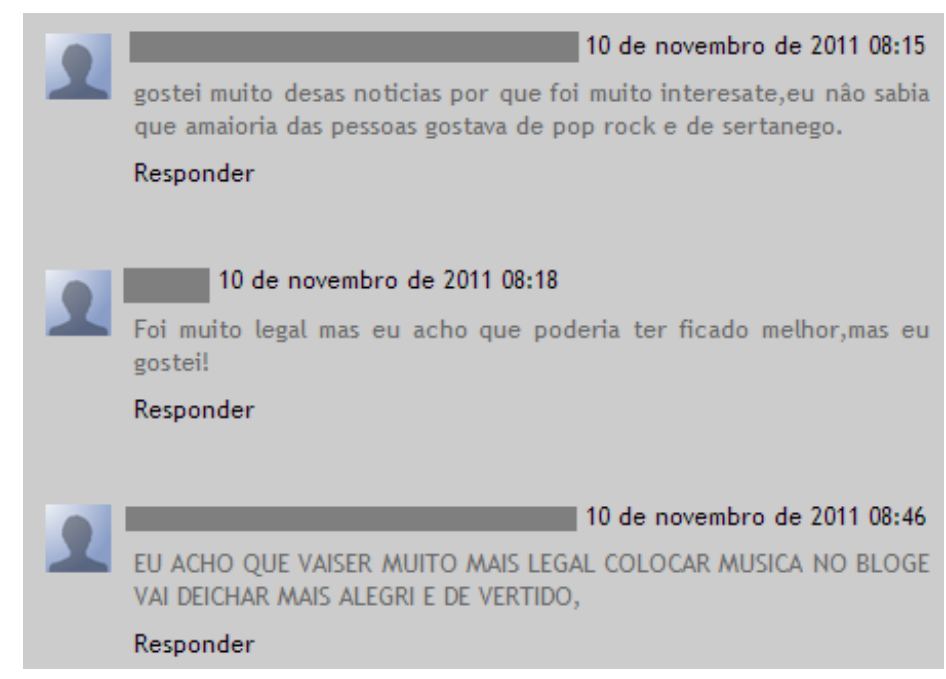

Figura 1: Comunicação entre os participantes: Projeto Um Mundo de Informações

$\mathrm{Na}$ figura 1, estudantes de um mesmo projeto dialogam sobre a postagem da notícia, comentando sobre os resultados apresentados e sugerindo o que pode ser feito futuramente para a melhoria do blog. 


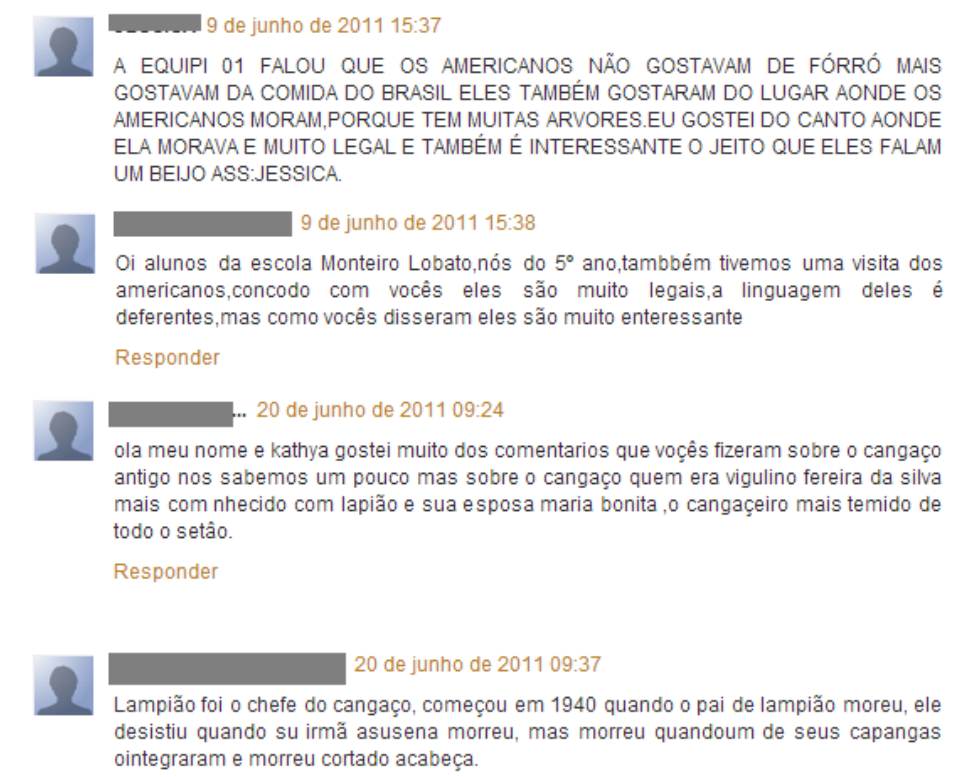

Figura 2: Recorte de postagem dos textos dos alunos:Projeto Nossos Lugares no Mundo

$\mathrm{Na}$ figura 2, após a postagem de textos produzidos pelas crianças do Projeto Nossos Lugares no Mundo, verificam-se comentários que buscam interpretar o que foi postado. Além dessas postagens, também há comentários acrescentando informações ao que já havia sido postado. Essas situações demonstram que a comunicação não foi baseada apenas na transmissão de conhecimento - comunicação reativa, mas contou com a interferência do interlocutor - comunicação interativa [Silva, 2010].

Para Silva (2010) é possível aprender com a nova modalidade comunicacional em que as aulas não são baseadas, apenas, na transmissão de conhecimento, mas na disposição de múltiplas opções à intervenção do interlocutor.

Assim, percebe-se nesses contextos apresentados situações em que os alunos, além de aprenderem com o professor, também aprendem entre si, resultando o que Freire (1996) chama de educação dialógica. É importante observar que, a comunicação de forma interativa no blog, através dos comentários dos estudantes, foi favorecida pela disponibilidade dos laptops educacionais nas salas de aula fazendo uso, para isso, da conectividade imersiva.

\subsection{Ampliação do tempo}

O blog dos dois projetos analisados utilizaram metodologias diferentes. Enquanto no Projeto Nossos Lugares no Mundo, os estudantes reuniam-se em horários de aula para produzir os textos que eram postados pela equipe do grupo PROATIVA, no Projeto Um Mundo de Informações as próprias crianças faziam as postagens das notícias no blog.

Para que as crianças do Projeto Um Mundo de Informações postassem no blog do projeto, foi necessário criar um e-mail comum que foi administrado pela professora da turma, mas com senha compartilhada para a turma inteira, já que as crianças tinham menos que 13 anos e pela política de segurança da internet não é permitido que crianças menores de 13 anos possuam conta no Gmail.

Ao ser fornecido todos os dados para que as crianças do Projeto Um Mundo de Informações acessassem o blog, houve questionamentos do tipo: "Tia, se eu quiser eu posso fazer lá em casa, no meu computador que minha mãe me deu?" (Informação 
verbal de uma aluna) e "Se eu quiser fazer lá na lanhouse, dá para fazer?" (Informação verbal de um aluno). Outros questionamentos das crianças desse projeto foram se podiam ir à escola em outros horários para acessar o blog pelo seu laptop, já que a escola não liberava os laptops educacionais para serem levados para casa. Diante desses questionamentos foi explicado que com os dados de acesso eles poderiam acessar o blog no momento que quisessem, bastando para isso, um computador e internet.

As crianças do Projeto Nossos Lugares no Mundo também acessavam o blog fora do horário de aula. Isso pode ser constatado no recorte de um comentário retirado do blog (figura 3), em que um dos estudantes do projeto menciona o fato de pedir dinheiro aos pais para poder acessar o blog do projeto em uma lanhouse.

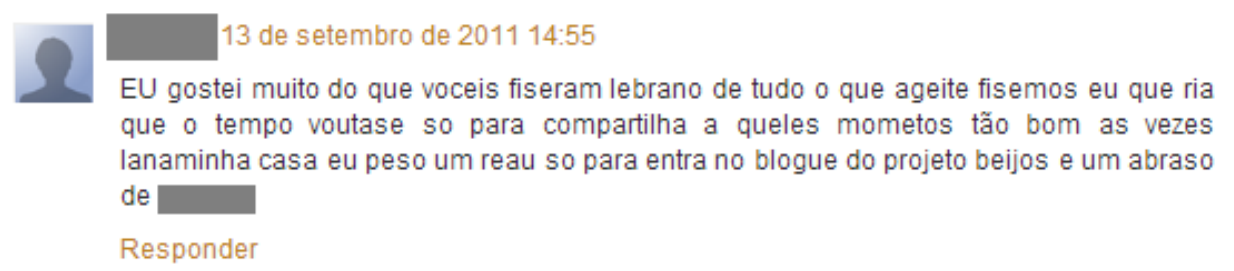

Figura 3: Recorte de comentário do blog: Projeto Nossos Lugares no Mundo

Observou-se, portanto, que apesar da diferenciação na metodologia utilizada nos dois projetos, a ampliação do tempo aconteceu, mesmo que de forma distinta. Em tempos diferentes ao horário de aula, as crianças dos projetos acessavam os blogs para comentar as postagens e, no caso das crianças do Projeto Um Mundo de Informações para produzir e postar as notícias proporcionando, portanto, o desenvolvimento da autonomia por parte desse grupo de estudantes.

Para Brazão (2008, p. 297), a integração da tecnologia, como o blog, em espaços pedagógicos pode, inicialmente, "respeitar um tempo definido, e gradualmente diluir-se noutros tempos curriculares, refletindo os aspectos da vida da sala", além disso, o mesmo autor cita que um dos ganhos no trabalho curricular é a autonomia, pois possibilita a mobilização do conhecimento através da reflexão de suas ações. Assim, entende-se que o uso do blog pode ser importante para dar continuidade fora de sala de aula ao estudo iniciado em sala de aula de maneira eficiente.

\subsection{Ampliação do espaço}

Com o uso do blog a sala de aula convencional passou a não ser mais o único espaço destinado à aprendizagem. Desta maneira, além da ampliação do tempo, discutido na categoria anterior, as análises mostraram que houve também uma ampliação do espaço.

Pode-se perceber, ao analisar os blogs dos projetos e em informações fornecidas pelos estudantes, que os blogs não foram usados, apenas, em sala de aula e nos momentos da aula. Os estudantes acessaram os blogs dos projetos em diferentes lugares: na sala de aula, no pátio da escola, no laboratório de informática educativa (LIE), em casa ou em lanhouses.

Para as publicações os alunos utilizaram as informações e dados coletados em outros espaços da escola e até da comunidade escolar, além de ter possibilitado a interação entre escolas em lugares distintos, como já mencionado (ver figura 4).

$\mathrm{Na}$ figura 4, observa-se que uma postagem em que um estudante da escola de Barreira relata algumas ações realizadas pelo professor e a turma em sala de aula. Nessa 
mesma postagem, percebe-se que o aluno tenta interagir com um aluno da escola de Fortaleza, ao solicitar explicações do significado de nick (apelido).

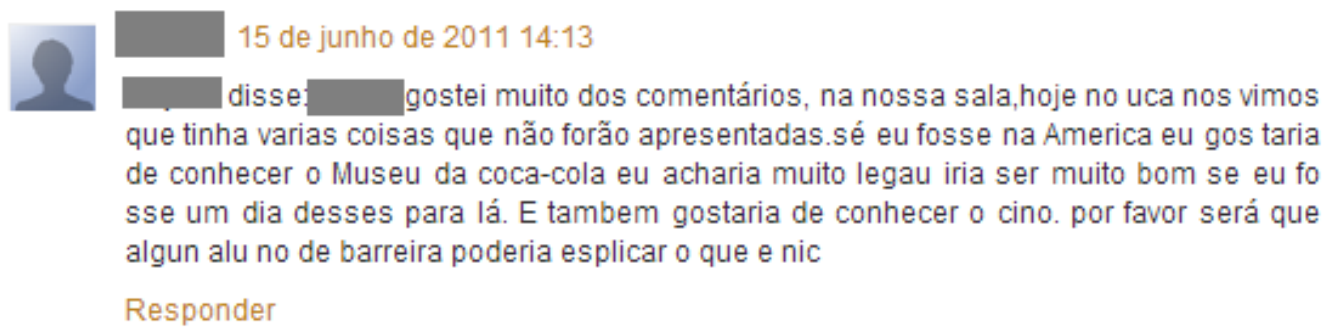

Figura 4: Recorte de comentário de aluno: Projeto Nossos Lugares no Mundo

No blog do Projeto Um Mundo de Informações os estudantes postaram uma notícia com o título: Poluição em todo lugar. Essa notícia foi construída a partir de informações coletadas pelos estudantes dentro e fora da escola, contando com a participação em entrevistas de professores e moradores da comunidade local.

O blog poder ser utilizado como ambiente virtual de aprendizagem [Dalsoquio, Haguenauer, 2011], proporcionando assim a ampliação do espaço de aprendizagem. A mobilidade dos laptops, no caso do Projeto Um Mundo de Informações, também foi determinante para a ampliação desses espaços [Castro, Castro-Filho, 2012], pois possibilitou que os estudantes saíssem da escola. Além disso, percebe-se que, como o tempo de aula não era suficiente para a realização dos trabalhos, as crianças passaram a utilizar seu tempo "livre" para a concretização dos trabalhos.

\subsection{Produção de materiais}

O blog dos dois projetos analisados possibilitou a produção de material a partir das postagens. No Projeto Nossos Lugares no Mundo foi produzido um objeto de aprendizagem (OA) a partir das trocas culturais realizadas através do blog pelos alunos das escolas de Fortaleza e Barreira que participavam do referido projeto.

O OA, denominado Museu $\mathrm{Virtual}^{2}$, conta com dois personagens, Craig $e$ Whitney, baseados nos alunos norte-americanos que participaram do referido projeto, que convidam o usuário a fazer um passeio virtual por um museu que possui cinco salas organizadas a partir das postagens dos trabalhos construídos pelos estudantes brasileiros ao longo do projeto.

No Projeto Um Mundo de Informações foi produzido um jornal digital a partir das atividades de investigação realizadas ao longo do projeto e postadas no blog pelas próprias crianças. As notícias foram produzidas utilizando o laptop educacional, o que facilitou a filmagem e as fotografias a partir da câmera disponível, e a conectividade imersiva que possibilitou o acesso a sites de busca de imagens, informações e objetos de aprendizagem para a construção de gráfico de barras e de setores e ao blog do projeto para a publicação das notícias.

Assim, para a produção dos textos que deram origem ao jornal digital ${ }^{3}$, os recursos existentes no laptop e na internet deram suporte a escrita das notícias, tornando os alunos sujeitos ativo nessa prática de produção. Para Gutierrez (2004) os blogs podem ser construídos e modificados, sendo, portanto, potencializadores da autoria.

\footnotetext{
${ }^{2}$ http://nossoslugaresnomundo.blogspot.com.br/2011/08/blog-post.html

${ }^{3}$ http://1mundodeinformacoes.blogspot.com.br/2012/01/jornal-digital.html
} 


\subsection{Aprendizagem colaborativa}

Durante a realização dos projetos, observou-se que as produções dos trabalhos aconteceram de forma coletiva, por meio da aprendizagem colaborativa com apoio dos laptops educacionais.

Segundo Dias (2001), a aprendizagem colaborativa faz parte de uma abordagem educacional que engloba processos e estratégias nas quais os alunos são encorajados a trabalhar conjuntamente para desenvolver e construir seu próprio conhecimento. Este tipo de aprendizagem necessita da interação entre os seus participantes: "Esta é a aprendizagem que não se realiza simplesmente na interação, mas que está realmente constituída nas interações entre participantes" [Stahl et al, 2006, p.12].

Para Vygotsky (1987, p. 17) "a colaboração entre pares ajuda a desenvolver estratégias e habilidades gerais de solução de problemas pelo processo cognitivo implícito na interação e na comunicação".

\section{Conclusão}

As análises dos blogs dos projetos de escolas UCA revelaram que foram desenvolvidas atividades com os estudantes, incluindo não somente a elaboração e publicação de conteúdo. Assim como apresentado, verificou-se que os blogs dos projetos, usados a partir do laptop educacional, possibilitaram a ampliação dos espaços de aprendizagem favorecendo a comunicação interativa, a ampliação do tempo, a ampliação do espaço, a produção de materiais e a aprendizagem colaborativa.

Além disso, os projetos possibilitaram a apropriação e o uso da Web 2.0 e de sua filosofia de colaboração. Apesar disso, mesmo considerando que esses se configuram como os primeiros passos para o uso destes recursos, vários outros ainda precisam ser explorados. Entende-se que o laptop educacional possibilita a realização de projetos que utilizam a Web 2.0, uma vez que além da mobilidade, proporciona a conectividade imersiva. Contudo, os estudantes ainda não possuem acesso total aos laptops, pois as escolas investigadas não permitem que os estudantes levem o equipamento para casa e a internet é muito precária.

Projetos como os descritos nesse trabalho possibilitam, além da aprendizagem dos conteúdos curriculares em que está vinculado, o desenvolvimento do senso crítico, da autonomia e da colaboração. Neste sentido, ressaltamos a importância de um projeto como o UCA que possibilita o suporte técnico e a formação docente que estimula e oportuniza a apropriação de novos recursos digitais.

\section{Referências bibliográficas}

Brazão, José Paulo Gomes. (2008) "Weblogs, aprendizagem e cultura da escola: um estudo etnográfico numa sala do $1^{\circ}$ ciclo do Ensino Básico". Funchal: Universidade de Madeira, 2008. $314 \quad$ p. $\quad$ Tese (Doutorado). Disponível em: http://hdl.handle.net/10400.13/127.

Castro, J. B.; Castro-Filho, J. A. (2012) "Um Mundo de Informações: Integração de Tecnologias Digitais ao Currículo Escolar”. In: I Congresso Brasileiro de Informática na Educação, 2012, Rio de Janeiro. Workshop sobre formação e experiências educacionais no programa Um Computador por Aluno do CBIE 2012, 2012. p. 1-10. Disponível em: http://www.brie.org/pub/index.php/wcbie/article/view/1902/1665 Acesso em 01 de dezembro de 2012.

Dalsoquio, Lais Cappaun; Haguenauer, Cristina Jasbinschek. (2011) "O Blog como Ambiente Virtual de Aprendizagem”. EducaOnline, Vol. 5, n. 3, p. 44-61, setembro/dezembro de 2011. 
Freire, Paulo.(1996) "Pedagogia da Autonomia: saberes necessários à prática educativa". São Paulo: Paz e Terra (Coleção Leitura).

Gutierrez, Suzana. (2004) "Mapeando caminhos de autoria e autonomia: a inserção das tecnologias educacionais informatizadas no trabalho de professores que cooperam em comunidades de pesquisadores". Porto Alegre: UFRGS, 2004. Dissertação (Mestrado). Programa de Pós-Graduação em Educação, Faculdade de Educação, Universidade Federal do Rio Grande do Sul, Porto Alegre.

Lakatos, Eva Maria; Marconi, Marina de Andrade.(1991) "Fundamentos de metodologia científica”. São Paulo: Atlas, 1991. 270 p.

Lave, J., Wenger, E. Legitimate peripheral participation in communities of practice. In M. R. Lea \& K. Nicoll (Orgs.), Distributed learning: Social and cultural approaches to practice (pp. 56-63). Londres: Routledge,2002.

Lemos, A. (1998) “Anjos interativos e retribalização do mundo: sobre interatividade e interfaces digitais". In: Signo Revista de Comunicação, João Pessoa, ano III, nº 5, p. 26-42.

Lima, L. L. V., Lima, Lucas. V. de; Barreto, D., Fernandes, A. C., Castro-Filho, J. A. (2011) "Interações multiculturais mediadas por computador: as percepções de dois participantes sobre o projeto Nossos Lugares no Mundo", in: XVII Workshop Sobre Informática na Escola - WIE - Informática na educação para a Democratização do Conhecimento, páginas 1924-1934. Anais.

Ludke, M.; André, Marli E. D. A. (1996) "Pesquisa em Educação: abordagens qualitativas". São Paulo: Ed. Pedagógica e Universitária.

Marinho, Simão P. P.; Tárcia, Lorena; Enoque, Cynthia F.; Vilela, Rita A. (2009) "Oportunidades e possibilidades para a inserção de interfaces da web 2.0 no currículo da escola em tempos de convergências de mídia”. Revista e-Curriculum, São Paulo, v. 4, n. 2, jun 2009.

Marinho et al, (2011) Uma proposta contextualizada de formação on-line de professores e gestores no Projeto UCA em Minas Gerais: possibilidades e desafios. in: Anais do XXII SBIE - XVII WIE, páginas 2015-2024.

Richardson, W. (2006) "Blogs, Wikis, Podcast and other powerful Web tools for classrooms". Thousand Oaks, CA: Corwin Press.

Sibilia, P. (2012) "Redes ou paredes: a escola em tempos de dispersão". Rio de Janeiro: Editora Contraponto.

Silva, M. (1998) “Que é Interatividade”.In: Boletim Técnico do Senac. Rio de Janeiro, v.24, n.2 maio/ago.

Silva, M. (2010) "Sala de aula interativa”. São Paulo: Edições Loyola, 2010.

Solomon, G.; Schrum, L.(2007) "Web 2.0: New Tools, New Schools". Eugene, Oregon: International Society for Technology in Education.

Stahl, G.; Koschmann, T.; Suthers, D. (2006) "Aprendizagem colaborativa com suporte computacional: Uma perspectiva histórica". Disponível em http://gerrystahl.net/cscl/CSCL_Portuguese.pdf, acesso abril 2011

Vygotsky. (1987) "A formação social da mente": desenvolvimento dos processos mentais superiores. São Paulo : Martins Fontes.

Warschauer, M. (2006). "Going one to one". The experiences of cutting-edge schools suggest the whys, the why nots, and the hows of laptop learning programs. In: Educational Leadership. December, 2005/January 2006.

Wenger, E.(2001) “Comunidades de práctica: aprendizaje, significado e identidad". Paidós Ibérica. 